\title{
Design and Assessment of Electric Vehicle Performance Parameters based on Drive Cycle
}

\author{
Binsy Joseph ${ }^{1, *}$ and Dr Deepak Vishnu Bhoir ${ }^{1, * *}$ \\ ${ }^{1}$ Department of Electronics Engineering, Fr Conceicao Rodrigues College of Engineering, Bandra(W), Mumbai-50, India
}

\begin{abstract}
Electric vehicle plays a significant role, in the future transportation across the world. EV has the potential to reduce air pollution and emission of Greenhouse gasses significantly compared to the existing fossil-fuel-based vehicles. Even though substantial progress can be expected in the area of embarked energy storage technologies, charging infrastructure, customer acceptance of Electric Vehicles is still limited due to the problems of Driving range anxiety and long battery charging time. We can solve most of these problems with the infrastructure development, optimum sizing and design of the vehicle components and extensive study on vehicle dynamics under various real-time driving conditions. This research focuses on the Matlab software based co-simulation of Electric Vehicle system, including the battery pack and motor, to predict the vehicle performance parameters like driving range, efficiency, power requirement, and energy characteristics under different driving scenarios. The vehicle's acceleration performance, energy consumption, and efficiency are determined by simulation and verified analytically. Using ADVISOR software the fuel economies and tail pipe emission for various vehicle models are determined by simulation and results are compared with Hybrid Electric vehicle models.
\end{abstract}

\section{Introduction}

In recent years, Electric Vehicle (EVs) have gained renewed interest in research and the automotive sector. Electric vehicle presents a tangible solution to reduce environmental pollution levels worldwide. Electric Vehicles and Hybrid Electric Vehicles have been regarded as the most promising alternative to Internal Combustion Engine (ICE) vehicle. Governments promote EV technology by providing subsidies and deploying public charging infrastructure in major city Highways and public parking places.Despite the fact that considerable advancement can be expected in embarked energy storage technologies, charging infrastructure, due to the problems of Driving range anxiety and battery charging speed limitation etc. To increase the customer acceptance of Electric vehicle, researchers and automotive companies are consistently working on modified, reliable and affordable vehicle models depending on the country wise requirements.

Electric Vehicles (EV's) batteries are charged from the grid. The charging process takes more time than refuelling of internal combustion engine vehicles. This problem significantly reduces the acceptance of EV's. Today's EV's are equipped with Li-ion batteries supporting a Fast Charging current[1]. Most modern EV's can accept a charging current of magnitude $\mathrm{xC}$ where $\mathrm{x}$ is the multiplication factor and $\mathrm{C}$ is the capacity of the battery[2].

The development of EV's starts changing the way that people travel. One of the major issue hindering the devel-

\footnotetext{
*e-mail: binsy_joseph@fragnel.edu.in

**e-mail: bhoir@fragnel.edu.in
}

opment of EV usage is range anxiety[3]. In this paper, we address the driving range estimation of an Electric vehicle, permitting drivers to beat range anxiety. This approach has the method of simplicity. This paper focuses on the analysis of vehicle energy consumption with the help of powertrain simulation and driving behaviour analyses.

When designing battery packs, it is important to be able to simulate the operation of the pack before actual fabrication. This helps to ensure that the pack will be able to meet all performance requirements before a large investment.

In order to understand the energy consumption of an actual Electric vehicle during real-world operating conditions and to evaluate the performance of various coupled Drive Train components before the actual fabrication and testing, manufacturers normally use sophisticated vehicle Co-simulation software. ADVISOR software is one commonly used software for Vehicle Simulation, but it has limited flexibility to simulate various design parameters of battery pack, motor specifications and vehicle parameters. Many researchers over the years studied different Optimization and simulation method to study vehicle performance under real-time driving conditions. A drive cycle is a time series of vehicle speed pattern created to simulate real world driving conditions. Driving cycles are utilized for assessing vehicle on-street energy utilization and vehicle emissions[4] . Jony J Eckert et al. studied Electric vehicle drive train optimization using a genetic algorithm to improve vehicle range and performance .Stephan Günther et al. investigated the influence of driving cycle on the design optimisation of permanent magnet syn- 
chronous motor drive for electric vehicle application [5]. Today's vehicle design mostly based on powertrain design and control, with no information on future driving plans[6]. Petru Palcu et al presented modelling and simulation results for Whole-Day Driving Prediction(WDDP vehicles on the real-world logged driving cycles of different drivers. Sanghpriya H. Kamble et al studied real world driving cycle for Indian city drive. They developed an urban driving cycle for estimating vehicular emissions and fuel consumption using micro-trips extracted from realworld data [7].

\section{Vehicle Dynamics and Powertrain Component Modelling}

This section discuss the modelling of complete EV drive train components and the basics of vehicle dynamics. The main difference between electric car and their conventional counterparts is in the drivetrain. Conventional ICE vehicle (Internal combustion Engine) has a multi speed gear box where as EV has a single speed transmission. In EV models, a single fixed -ratio transmission is used, consist of single reduction gear. Several Electric car models like Tesla Model S, Chevrolet Bolt, Nissan Leaf etc. use a single speed transmission coupled with electric motor which reduces emissions and eliminate the use of clutch. As per the speed, torque is varied automatically and vehicle operate at high efficiency.

\subsection{Electric Vehicle Power Train}

The powertrain of a Electric Vehicle (EV) consists of an electric drive system with a battery as an energy source and driven by an efficient electric motor, normally an Induction Motor. The chemical energy stored in the battery pack is used to drive the motor with the help of a Power Electronic Converter, accompanied by a control system. The control system controls the frequency and magnitude of the output of the Inverter depending on the driver's commands which are communicated through sensors connected to acceleration and brake pedal.

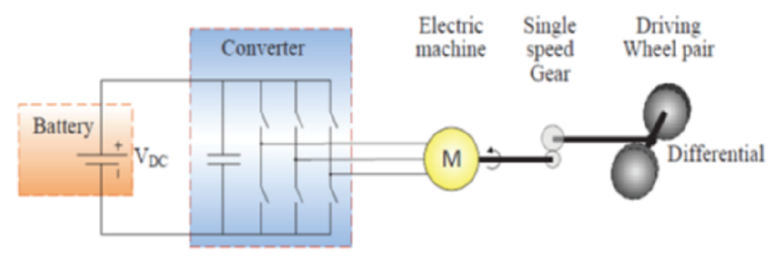

Figure 1. Schematic sketch of BEV powertrain

Electrical machines are normally designed with higher speed levels typically to reduce the physical volume of the machines. Gears are used for speed reduction at the wheels. To give the left and right wheels to have somewhat different speeds during turning, there is additionally a need for differential between the wheels.

\subsection{Vehicle Dynamics}

Vehicle dynamics describes how a vehicle moves forward affected by frictional powers between the tyre and the road.

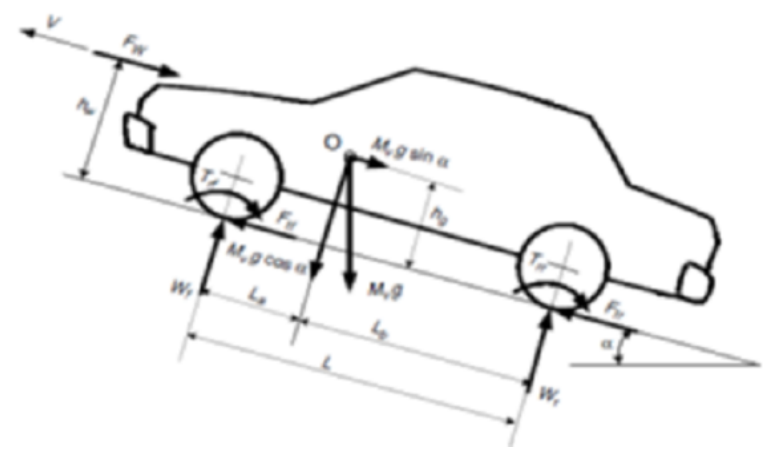

Figure 2. Forces acting on vehicle [9]

Understanding vehicle dynamics is very important while analyzing the impact of power train on vehicle performance to determine whether to accelerate or average energy consumption for a driven distance.

As per Newton's second law, vehicle acceleration can be written as

$$
m a=m \frac{d v}{d t}=F_{\text {tractive }}(t)-F_{\text {resistive }}(t)
$$

' $\mathrm{m}$ ' is the equivalent mass of the vehicle in $\mathrm{Kg}$, $a\left(m / s^{2}\right)$ is the acceleration, $F_{\text {tractive }}(t)(\mathrm{Nm})$ is the sum of all the tractive forces and $F_{\text {resistive }}(t)$ is the total resistive forces. The tractive force is applied from the powertrain through the gear, differential and the wheel shaft to the contact region between the wheels and the road.

Aerodynamic drag is the major resistive force acting on the vehicle while moving. Because of the complex shape of automobiles and complex nature of fluid dynamics, it is difficult to model accurate analytical model even using CFD(Computational Fluid Dynamics)software. Mathematically aerodynamic drag force is given by

$$
F_{a}=\frac{1}{2} \rho_{a} C_{d} A_{f}\left(V_{\text {vehicle }}-V_{\text {wind }}\right)^{2}
$$

$\rho_{a}\left(\mathrm{~kg} / \mathrm{m}^{3}\right)$ is air density, $C_{d}$ is aerodynamic drag coefficient, $A_{f}\left(\mathrm{~m}^{2}\right)$ cross-sectional area of the vehicle, $V_{\text {vehicle }}(\mathrm{m} / \mathrm{s})$ vehicle speed, and $V_{\text {wind }}(\mathrm{m} / \mathrm{s})$ is wind speed moving in the direction of the vehicle. The rolling resistance force, $F_{r}$ acting on a vehicle in the longitudinal direction, is

$$
F_{r}=C_{r} m g \cos (\alpha)
$$

where $\mathrm{m}$ is vehicle mass, $\mathrm{g}$ is gravity constant, $\alpha(\mathrm{rad})$ is road inclination angle.

The grad force, $F_{g}$ and wheel force $F_{\text {wheel }}$ acting on a vehicle is

$$
F_{g}=m g \sin (\alpha)
$$




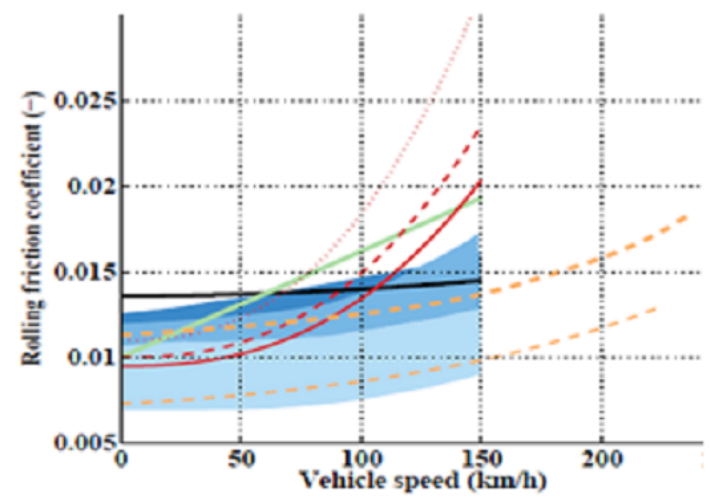

Figure 3. Rolling Frictional coefficient Vs Vehicle speed[10].

$$
F_{\text {wheel }}(t)=F_{a c c}(t)+F_{a}(t)+F_{r}(t)+F_{g}(t)
$$

$F_{a c c}(\mathrm{Nm})$ is the force required to accelerate the vehicle mass at a certain magnitude of acceleration.

\subsection{Differential}

All vehicles need a type of differential. It is imperative when turning a vehicle. To turn securely, the external wheels should turn quicker than the internal wheels, provided by differential.

\subsection{Wheel Power and Energy}

The wheel power $P_{\text {wheel }}$ is determined by the tractive force $\left(F_{\text {wheel }}\right)$ and the vehicle speed $\left(V_{\text {vehicle }}\right)$ as

$$
P_{\text {wheel }}(t)=F_{\text {wheel }}(t) . V_{\text {vehicle }}(t)
$$

The total energy at the wheel can be found from the time integral of the power as

$$
E_{\text {wheel }}(t)=\int P_{\text {wheel }}(t) d t
$$

\subsection{Modelling of Electric Motor}

An electric motor converts stored electric energy in the battery into mechanical energy to move the vehicle. It can also act as generator, gathering the mechanical power from the transmission to recharge the battery. Torque-power region is divided 2 stages: into constant torque, constant power and high speed region. Electric vehicles, do not require a multi-gear transmission. It start from zero speed and do not any consume any fuel. Thus contributes to a better efficiency without polluting emissions.

\subsubsection{Modelling of Permanent Magnet Synchronous Machine}

A Permanent Magnet Synchronous Machine (PMSM) consist of a rotor with permanent magnets and a wound stator.

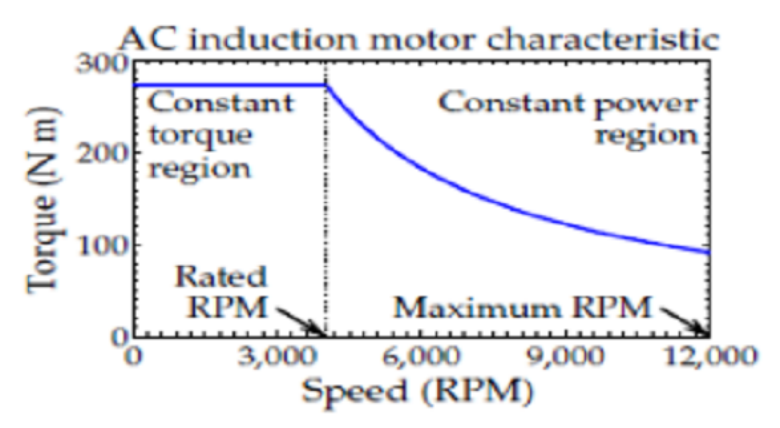

Figure 4. Torque-speed characteristics of Induction motor.

Equivalent circuit model: The commonly used model is the equivalent dynamic dq-model of a PMSM which is shown in Figure 5, where dq denote the rotor frame of reference or synchronous coordinates. Direct axis (d-axis) and Quadrature axis (q-axis) $90^{\circ}$ displaced.
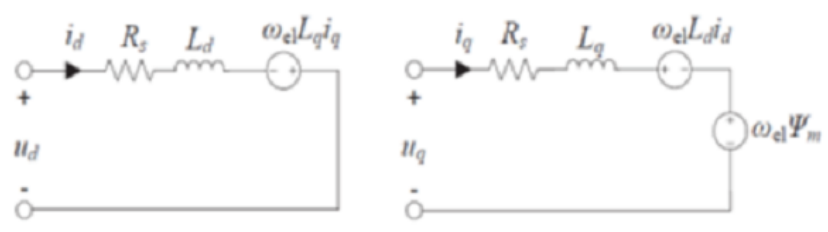

Figure 5. Equivalent circuit model of a PMSM machine

The stator voltage equations as functions of the dq axis stator currents $\left(i_{d}\right.$ and $\left.i_{q}\right)$ are;

$$
\begin{gathered}
U_{d}=L_{d} \frac{d i_{d}}{d t}+R_{s} i_{d}-\omega_{e l} L_{q} i_{q} \\
U_{q}=L_{q} \frac{d i_{q}}{d t}+R_{s} i_{q}+\omega_{e l} L_{d} i_{q d}+\omega_{e l} L \phi_{m}
\end{gathered}
$$

where $R s$ is stator winding resistance, $\omega_{e l}$ is angular speed $\left(\omega_{e l}=n_{p} W_{r}\right), W_{r}$ is rotor angular speed, and $n_{p}$ is number of pole pairs, $L_{d}$ and $L_{q}$ are dq-axis winding inductance, and $\phi_{m}$ is flux linkage related to the permanent magnet.

\section{Methodology}

A robust methodology is followed for developing a simple, cost-effective and general-purpose Electric vehicle simulation model using Matlab software. The results are verified with Standard vehicle simulation model using ADVISOR software.

The steps involved in this methodology are a selection of Test Electric Vehicles model with its specification, collection of drive data(speed Vs Time) under which Electric vehicle performance is evaluated using a computer programme, Experimentation, Test Data generation and Drive Cycle Validation, Analysis of performance of EV and Assessment efficiency of all components in the Electric drive drain including Battery pack, Power Converter and Electric Motor. 


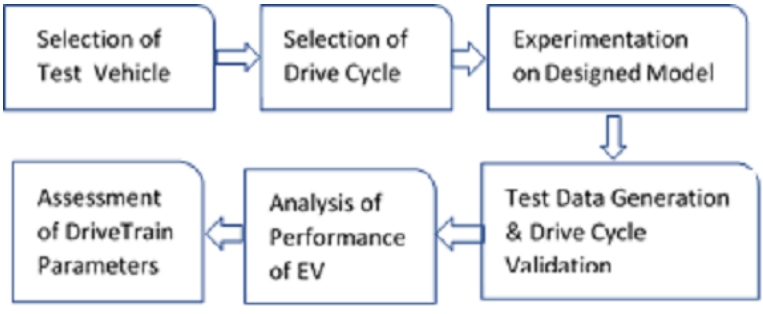

Figure 6. Block diagram of the methodology

To simulate an EV, an accurate description of vehicle and knowledge of the task the vehicle is required to accomplish are needed.The vehicle description includes all factors needed for dynamic simulation,including drivetrain characteristics ,battery-pack characteristics, motor and inverter characteristics. The vehicle driving patteren is simulated with drive-cycle profile( desired speed Vs time ). The urban dynamometer driving schedule (UDDS) profile is used to analyse city driving and highway fuel efficiency test (HW-FET) to predict EV performance in highway driving. Simulation approach is to compute on a sample by sample basis, the desired acceleration as per selected drive cycle profile,to match the desired speed profile and estimate achievable torque and power values by electric vehicle.The desired toque and power values are restricted by the specification of the motor chosen for the vehicle.

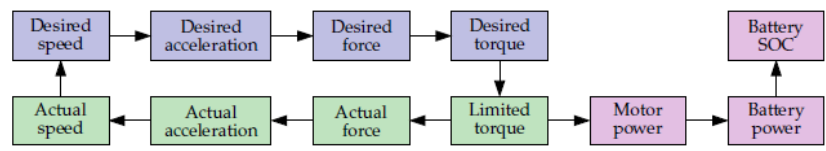

Figure 7. Simulation strategy

The battery power computed based on motor power and battery state of charge (SOC) is estimated and projected driving range of the electric vehicle is extrapolated from the remain battery SOC data.

To determine vehicle range based on battery capacity, battery pack must be simulated with the vehicle and load.Instantaneous power required by the motor is given by

$$
\text { MotorPower }=2 \pi * \frac{\text { Motorspeed } * \text { Torque }}{60}
$$

Battery Power is calculated as Battery Power = overhead power + motor Power $* \eta_{\text {drivetrain }}$

where $\eta_{\text {drivetrain }}$ is the efficiency of drivetrain

$$
\text { Batterycurrent }=\frac{\text { batterypower }}{\text { batteryvoltage }}
$$

Battery SOC at $k^{\text {th }}$ instant is updated as

BatteryS OC $C_{k}=[$ BatteryS OC $k-1]-\frac{\text { BatteryCurrent } * \Delta t}{\text { BatteryCapacity } * 3600}$
Driving range of the vehicle is calculated from SOC and total distance of simulated drive cycle (TotDistance ${ }_{d c}$ ) as

$$
\text { range }=\text { TotDistance }_{d c} * \frac{\left(S O C_{\text {max }}-S O C_{\text {min }}\right)}{\left(S O C_{\text {initial }}-S O C_{\text {end }}\right)}
$$

\section{Simulation Result and Discussion}

For the purpose of verification, the values of a conceptualized EV obtained from the system using the parameters either specified by the manufacturer or calculated using the formulas mentioned above are compared to the values of a vehicle of the same make and model. This helps in proving the effectiveness of the system and also proves the relevancy of the system with the current automotive industry standards. The vehicle which is being used as a test benchmark is the General Motors Chevy Volt operating in pure electric mode. Vehicle performance is simulated for City Drive cycle (UDDS) and Highway drive cycle (HWFET ).

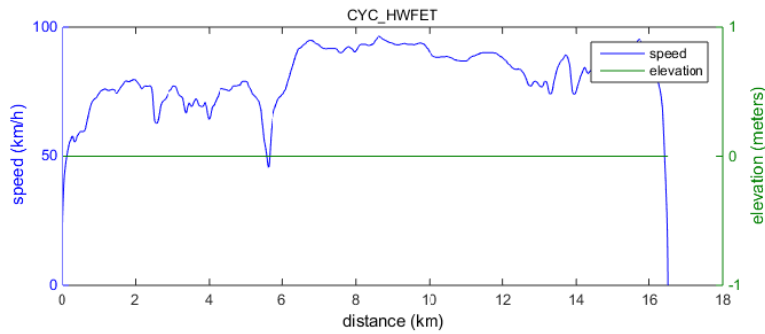

Figure 8. Highway drive cycle (HWFET)

ADVISOR software is used to compare the performance of conventional Gasoline powered vehicle and Hybrid vehicle. Using this software various vehicle models including conventional and Hybrid Electric vehicle(HEV) are simulated over city and Highway drive cycle and results are tabulated.

\section{Fuel Economies (Miles per Gallon) for Simulated} Vehicular Drivetrains

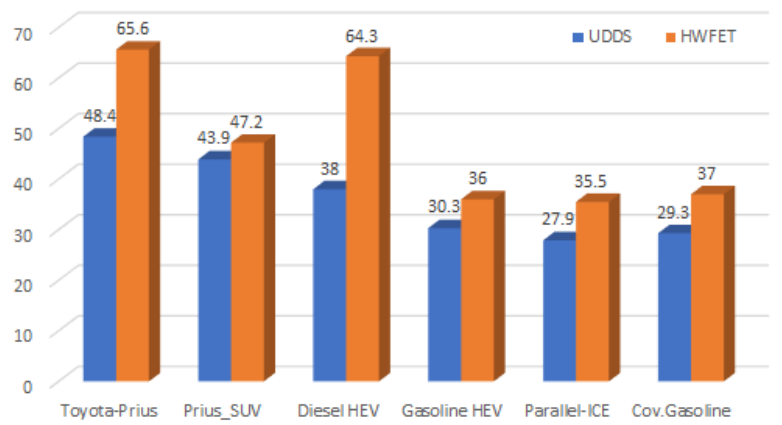

Figure 9. A Fuel Economies (mpg) obtained for various vehicle.

Fuel economies in Miles per Gallon for Hybrid drivetrain vehicle models (HEVs )are much better than conventional counterparts as shown in Fig.9. 
Different vehicle models are simulated over UDDS and HWFET drive cycle.Simulated vehicle's fuel consumption and emission results are shown in Fig.10.

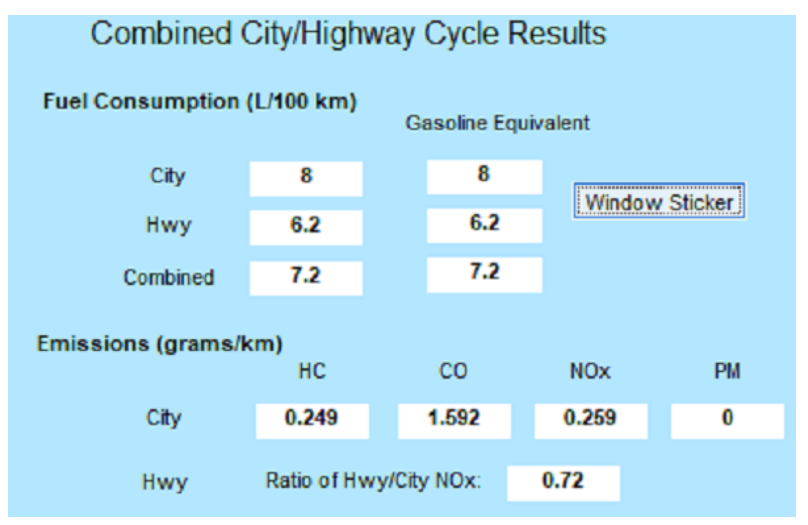

Figure 10. Fuel consumption and Emission result

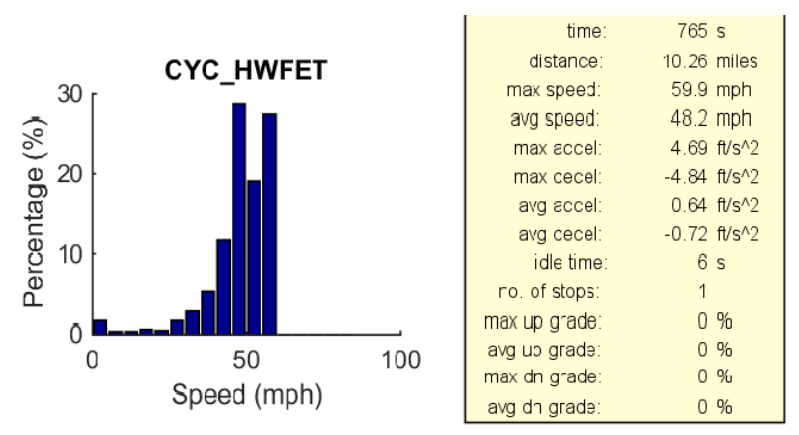

Figure 11. HWFET drive cycle, EV speed Profile

For simulated vehicle model ,the difference between requested and obtained vehicle speed $(\mathrm{km} / \mathrm{h})$ profile under the UDDS drive cycle is shown in Fig.12. Simulated Electric Vehicle Speed profile is plotted in Fig. 11.

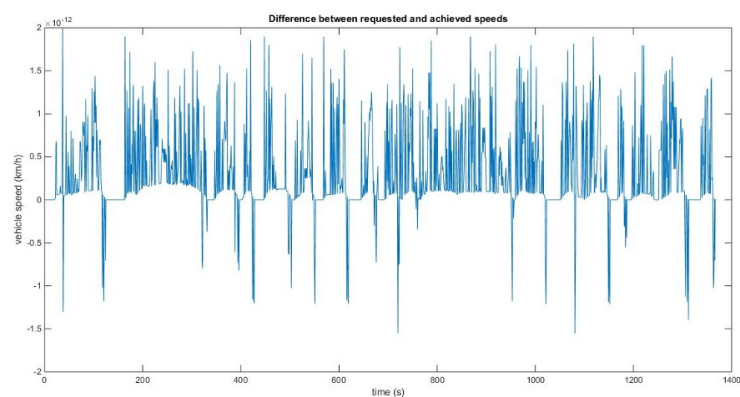

Figure 12. Difference between requested and achieved speeds

Fig.12 shows the difference between requested and achievable vehicle speed under selected driving profile. Vehicle performance is evaluated using simulation and Torque-Speed characteristics is plotted in Fig.13.

EV models, General Motors Chevy Volt operating in pure electric mode,is simulated using proposed algorithm using Matlab software. Vehicle specifications used for

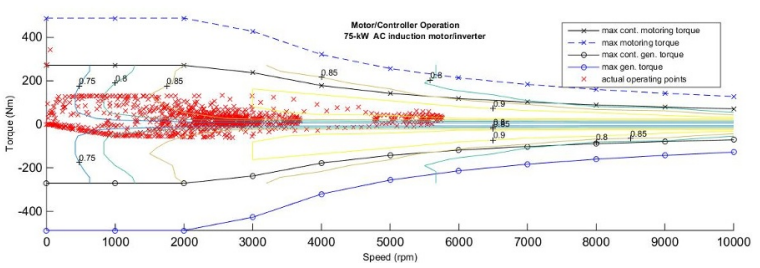

Figure 13. Motor Speed -Torque Characteristics

Table 1. Vehicle Specification:

\begin{tabular}{lll}
\hline SrNo & Description & Value \\
\hline 1 & Weight & $1500 \mathrm{Kg}$ \\
\hline & Aerodynamic Frontal Area & $1.84 \mathrm{~m}^{2}$ \\
\hline & Drag coefficient Cd & 0.22 \\
\hline & Constant Overhead power & $200 \mathrm{~W}$ \\
\hline & Wheel rolling radius & $0.35 \mathrm{~m}$ \\
\hline & Rolling coefficient Cr & 0.0111 \\
\hline & Gear ratio & $12: 1$ \\
\hline & Gear Inertia & $0.05 \mathrm{~kg} / \mathrm{m}^{2}$ \\
\hline & Gear efficiency in percent & 97 \\
\hline 2 & Battery nominal voltage & $3.8 \mathrm{~V}$ \\
\hline & Cell capacity & $15 \mathrm{Ah}$ \\
\hline & Battery module & $3 \mathrm{P} 8 \mathrm{~S}$ \\
\hline & Battery pack & $12 \mathrm{modules}$ \\
\hline & Pack nominal Voltage & $365 \mathrm{~V}$ \\
\hline 3 & Inverter efficiency & 90 \\
\hline & Motor max torque & $275 \mathrm{Nm}$ \\
\hline & Rated speed RPM & $4000 \mathrm{rpm}$ \\
\hline & Max speed & $12,000 \mathrm{rpm}$ \\
\hline & Motor efficiency & 95
\end{tabular}

simulation are tabulated in Table 1. All vehicle parameters are stored as structure and passed to Matlab function for each specific task. System is modelled and Software program is written for each specific module using the mathematical model and formulas discussed.The vehicle performance parameters are analysed and plotted.

\section{Conclusion}

This project focuses on the Matlab based simulation of Electric Vehicle system to predict the vehicle performance parameters like driving range, efficiency, power requirement, and battery current demand under different driving 
scenarios. This work also discuss the advantages of converting an conventional vehicle to an $\mathrm{EV}$ and also we can protect the environment by reducing the usage of fuel. The absence or reduction of tailpipe emissions results in improving the air quality and removal of greenhouse gas emissions. The additional benefit of using electricity is that there is a greener option to charge from renewable power thus benefiting the planet. The system also calculates the capacity of the battery which will be needed to run the vehicle for a said amount of distance, thus, providing the manufacturer the ideal battery capacity. In this paper, we address the strategy for assessing the driving range of an Electric vehicle, permitting drivers to defeat range tension.

\section{References}

[1] Christen, Daniel and Jauch, Felix and Biela, Jurgen, Ultra-Fast Charging Station for Electric Vehicles with integrated split Grid Storage,17th European Conference on Power Electronics and Applications, EPE'15, ECCE-Europe, 2015, 1-11

[2] Bertoluzzo M, Buja G, Pede G.Design considerations for fast AC battery chargers. (World Electric Vehicle Journal, 2013) 147-154.
[3] B. Joseph and D.V. BhoirDesign and Simulation of Wireless Power Transfer for Electric Vehicle, (2019 Int. Conf. Adv. Comput. Commun. Control, 2019) 1-5.

[4] S. K. Pathak, Y. Singh, V. Sood, and S. A. ChanniwalaDrive Cycle Development for Electrical Three Wheelers, (SAE Tech. Pap., vol. 2017-March, 2017)

[5] S. Günther, S. Ulbrich, and W. Hofmann,Driving Cycle-Based Design Optimization of Interior Permanent Magnet Synchronous Motor Drives for Electric Vehicle Application, (2014) pp.25-30

[6] P. Palcu and J. BaumanWhole-Day Driving Prediction Control Strategy: Analysis on Real-World Drive Cycles, (IEEE Trans. Transp. Electrif., vol. 4, no. 1, 2017) pp.172-183

[7] S. H. Kamble, T. V. Mathew, and G. K. Sharma,Development of real-world driving cycle: Case study of Pune, India, (Transp. Res. Part D Transp. Environ., vol. 14, no. 2, 2009) pp. 132-140

[8] C. Daniel Pires Rodrigues, J. Humberto Oliveira Seabra Co-Advisor, and J. António dos Santos Almacinha,Design of a high-speed transmission for an electric vehicle.

[9] A. E. Mehrdad Ehsani, Yimin Gao,Modern Electric ,Hybrid Electric and Fuel cell vehicles Fundamentals, Theory and DesignBook.1390

[10] R. Carlos Daniel Pires,Design of a high-speed transmission for an electric vehicle, (2018) pp. 309 